\title{
Um tipo de justiça infalível: a Justiça Eterna
}

\author{
Felipe dos Santos Durante \\ Mestrando em Filosofia - UNICAMP/Bolsista da FAPESP
}

\begin{abstract}
RESUMO: Este artigo tem por objetivo expor em linhas gerais o conceito de Justiça Eterna (ewige Gerechtigkeit) formulado por Arthur Schopenhauer.

PALAVRAS-CHAVE: Schopenhauer, Ética, Justiça Eterna.
\end{abstract}

ABSTRACT: This article aims to show, in general lines, the concept of Eternal Justice (ewige Gerechtigkeit) formulated by Arthur Schopenhauer.

KEYWORDS: Schopenhauer, Ethics, Eternal Justice.

É possível notar, ao longo do quarto livro de $O$ mundo como vontade e como representação, ${ }^{1}$ a utilização do conceito de Justiça (Gerechtigkeit) em três registros: (i) a Justiça como Virtude, ${ }^{2}$ (ii) como Justiça Temporal (zeitliche Gerechtigkeit), e (iii) como Justiça Eterna (ewige Gerechtigkeit). A primeira ocorrência para o uso da Justiça pode ser entendida como um certo grau no desvelar o Véu de Maia, um certo olhar através do princípio de individuação que faz com que o indivíduo abdique em parte de seu egoísmo, fazendo menor distinção entre si mesmo e os outros. O segundo tipo de justiça afirma-se como tal quando a ação realizada para evitar uma ação injusta refere-se ao futuro (Zukunft); ela tem no Estado seu dispositivo, seu meio para efetivar-se,

\footnotetext{
1 Adotou-se a edição das obras completas em alemão organizadas por Paul Deussen: SCHOPENHAUER, A. Arthur Schopenhauers sämtliche Werke; hrsg. Von Paul Deussen. Munique: R. Piper, 1911-1942. A tradução adotada de Die Welt als Wille und Vorstellung para uma leitura cotejada com a obra em idioma alemão foi feita por Jair Lopes Barboza: O Mundo como Vontade e como Representação, $1^{\circ}$ Tomo; São Paulo: Editora UNESP, 2005. Doravante abreviado como MVR I, seguido da indicação de parágrafo e página, e do tomo e da paginação em referência à edição alemã.

Para a leitura cotejada das notas de aula (Vorlesungen) sobre a ética (Arthur Schopenhauers handschriftlicher Nachlaß. Philosophische Vorlesungen - Metaphysik der Sitten. In: SCHOPENHAUER, A. Arthur Schopenhauers sämtliche Werke, vol X; hrsg. Von Paul Deussen. Munique: R. Piper, 19111942, p.367-584), adotou-se a tradução espanhola feita por Roberto Rodríguez Aramayo (Metafísica de las Costumbres; introdução, tradução e notas de Roberto Rodríguez Aramayo. In: Coleção Clássicos de la Cultura; Madri: Editorial Trotta SA, 2001). Doravante abreviado como MP, seguido de indicação de capítulo, página e da paginação em referência à numeração dos manuscritos originais.

${ }^{2}$ Em seu artigo Schopenhauer's Theory of Justice and its Implication to Natural Law, Annette Godart-van der Kroon nomeia este tipo de justiça como Voluntary Justice. Preferiu-se utilizar o termo Justiça como Virtude ao termo Justiça Voluntária porque o primeiro não transmite a possibilidade do agir justo ser entendido como um posicionamento ético intencional livre.
} 
podendo, assim, retaliar e punir. Por fim, a terceira, exposta no $§ 63$ de $M V R I$, rege o mundo.

A Justiça Eterna independe das instituições humanas e não está submetida ao acaso e ao engano, não sendo, dessa forma, incerta nem oscilante, mas infalível, firme e certa. Ela não requer a mediação do tempo, do espaço, e da causalidade para compensar um ato maldoso, através de conseqüências ruins. Dessa forma, ela independe da experiência. Ademais, apesar dela reger o mundo, isso não significa que ela balanceia uma injustiça cometida (ausgeübten Unrechts) em um lugar com um sofrimento em outro lugar: nela, a punição tem de ser tão ligada à injúria que ambas se tornam unas.

Destarte, a Justiça Eterna reside, segundo Schopenhauer, na essência do mundo, ${ }^{3}$ na coisa-em-si, revelando, assim, o seu caráter metafísico; ou seja, ela não considera o mundo enquanto fenômeno, i.e., ela não considera o sofrimento particular ou a mesquinhez de cada indivíduo, ${ }^{4}$ não podendo ser encontrada na experiência. Para ser apreendida, então, é preciso adotar o ponto de vista transcendental. Esse ponto de vista permite entender que a finitude, o sofrimento, e os tormentos deste mundo são expressões daquilo que a Vontade quer, e, conseqüentemente, configuram-se de maneira consoante com a forma da Vontade querer: tal qual é a Vontade, é o mundo. ${ }^{5}$ E o que é Vontade? Um impulso cego e irracional que traz em si a marca ontológica da sua insatisfação eterna, discórdia. Todo ato de Vontade satisfeito é apenas uma transição para um novo ato de querer da Vontade. Portanto, ela nunca pode ser satisfeita, ela é eternamente padecente. O mundo não é mais que o espelho dessa volição, dessa autodeterminação da Vontade. ${ }^{6}$ Essa constatação, em sua última consequiência, leva Schopenhauer a concluir que "[...] tudo o que acontece ou pode acontecer a cada um, a justiça sempre lhe é feita, pois sua é a Vontade". ${ }^{7}$ Essa afirmação é mais bem formulada quando o filósofo escreve que:

\footnotetext{
${ }^{3}$ Cf. MVR I, §63, P. 449, I 415.

4 "Schopenhauer, nesse ponto, não está tecendo comentários acerca do sofrimento individual de cada ser humano e da mesquinhez de cada um" (tradução livre para: "Schopenhauer is not at this point commenting on individual human suffering and individual human vileness"). HAMLYM, D.W. Eternal Justice. In: Jahrbuch der Schopenhauer-Gesellschaft, 1988. Band 69. Frankfurt am Main: Verlag Waldemar Kramer, 1988. P.281.

${ }^{5}$ Cf. MVR I, §63, P. 449, I 415. Nesta chave de leitura, pode-se entender o conceito de Justiça Eterna como uma tautologia: ele enuncia que o mundo é o que é.

${ }^{6}$ Cf. MVR I, §63, P. 449, I 415.

${ }^{7}$ MVR I, §63, P. 449, I 415.
} 
Se os homens, tomados como um todo, não fossem tão indignos, então seu destino, também tomado como um todo, não seria tão triste. Nesse sentido podemos dizer: o mundo mesmo é o tribunal do mundo. Pudesse alguém colocar toda a penúria do mundo em UM prato da balança, e toda a culpa no outro, o fiel permaneceria no meio. ${ }^{8}$

O mundo é o tribunal do mundo significa que do ponto de vista metafísico, o mundo é perfeitamente retributivo e retaliativo (vergeltende), ${ }^{9}$ que a punição já está em nós mesmos: nascer é um delito, pois, conforme uma lei eterna, a morte vem depois. ${ }^{10}$ Essas asserções são expressas por alguns comentadores de Schopenhauer de maneira pontual, como a de Alexis Philonenko que enuncia: "a fatalidade é a verdadeira justiça que se traduz em tragédia", ${ }^{11}$ ou quando Marie-José Pernin escreve que "somos o que temos merecido ser". ${ }^{12}$ Ambos referem-se a um tipo de justiça que vem-a-ser, com justeza, a partir da expressão da Vontade objetivada no agir, e que, assim, expõe a essência de dor e sofrimento do mundo.

Contudo, o indivíduo comum não consegue ter acesso para além do mundo fenomênico, para além do princípio de individuação: ele não intui a coisa-em-si, a essência das coisas, mas apenas experiencia os fenômenos fragmentados e situados espaço-temporalmente em uma cadeia causal dessa Vontade que é una noumenicamente. Devido a essa inacessibilidade, dessa deficiência em perceber a mesma essência metafísica nos diversos fragmentos de Vontade objetivados no mundo como representação, o indivíduo não consegue apreender e entender o significado da Justiça Eterna, nem perceber a retaliação / retribuição no mundo, o delito que é viver.

\footnotetext{
${ }^{8}$ MVR I, §63, P. 450, I 415. Pode-se dizer que, em nossa chave de leitura, penúria e culpa são apenas rótulos diferentes para uma mesma, por assim dizer, essência colocada em dois pratos de uma mesma balança.

${ }^{9}$ Cf. CARTWRIGHT, D. E. Historical Dictionary of Schopenhauer's Philosophy. In: Historical dictionaries of religions, philosophies, and movements, $n^{\circ}$. 55; Oxford: Scarecrow Press, 2005, P. 46. Deve-se frisar que essa retaliação / retribuição (vergeltende) deve ser entendida do ponto de vista metafísico, uma vez que é necessária a adoção do ponto de vista transcendental para o entendimento do significado da Justiça Eterna. Trata-se do em-si dos homens, do fato da humanidade, considerada em sua totalidade, ser o que ela não deveria ser, ser o que ela tem merecido ser, ser o que ela é. Além do fato de que, do ponto de vista fenomênico, a retaliação / retribuição implica a temporalidade, e como visto, a Justiça Eterna independe do princípio de individuação. (Cf. MVR I, §63, P. 448, I 415).

${ }^{10}$ Cf. MVR I, §63, P. 453, I 419.

11 PHILONENKO, A. Schopenhauer - Una Filosofía de la Tragédia. Tradução de Gemma MuñozAlonso López. Barcelona: Anthropos Editorial Del hombre, 1989. P. 205.

12 PERNIN, M. Schopenhauer - Decifrando o Enigma do Mundo; Tradução de Lucy Magalhães. RJ: Jorge Zahar, 1995. P.34
} 
Mas, qual seria a possível causa responsável por essa incapacidade dos indivíduos em perceberem a univocidade metafísica de suas essências? Schopenhauer utiliza-se de uma bela metáfora para explicar essa inferência. Ele compara o indivíduo comum a um barqueiro que se apóia e confia firmemente em sua pequena e frágil embarcação, em meio a um oceano sem fim. O barqueiro seria o indivíduo, o oceano os sofrimentos e dores do mundo, e a pequena e frágil embarcação, na qual o indivíduo se apóia e confia firmemente, o princípio de individuação.

Schopenhauer argumenta que as formas cognitivas do fenômeno separam o indivíduo do mundo restante. Essa separação reside exclusivamente no fenômeno, não na coisa-em-si, pois é no fenômeno que existe a pluralidade. E, como visto, precisamente neste ponto, na coisa-em-si, na essência dos seres, é que repousa a Justiça Eterna. ${ }^{13}$ Essa se furta ao olhar turvado pelo conhecimento que segue o princípio de razão e o princípio de individuação. Como Icilio Vechiotti assinala: "a justiça eterna consiste na tomada de consciência da unidade das coisas como Vontade". ${ }^{14}$

Se a essência do mundo é sofrimento, então cada indivíduo carrega em si, enquanto fragmentação dessa essência, todos os sofrimentos do mundo como seus; cada um traz dentro de si um inferno. Mas, para conceber e apreender o significado da Justiça Eterna, o indivíduo precisa elevar-se por sobre o conhecimento que segue o fio condutor do princípio de razão: ele precisa abandonar o ponto de vista da individuação e adotar o ponto de vista transcendental. Ao conseguir realizar tal tarefa, o sujeito perceberá que, em essência metafísica, ele e os demais fenômenos que lhe aparecem são expressão de uma mesma Vontade: ele apreenderá que a vítima e o carrasco são a mesma Vontade, e, portanto, unos; que a vontade, a todo instante, crava os dentes em sua própria carne. Essa apreensão, o conhecimento do significado da Justiça Eterna, faz com que o indivíduo perceba a impossibilidade de separação entre o malum culpae e o malo poenae. $^{15}$

São poucos os que conseguem realizar a tarefa de abandonar o ponto de vista da individuação e, conseqüentemente, o princípio de individuação, para apreender o significado da Justiça Eterna. Não é na experiência que o indivíduo encontrará a Justiça Eterna. Mas a transmissão de tal conhecimento pode ser feita por diferentes formas: (i)

\footnotetext{
${ }^{13}$ Isto é, na Vontade, o que está de acordo com a asserção dos demais comentadores citados.

14 VECCHIOTTI, I. Schopenhauer. Trad. de João Gama. In: Biblioteca Básica de Filosofia. Lisboa: Edições 70, 1990, P. 44.
} 
de modo esotérico, aos iniciados, explica-se tal apreensão, via Upanixade e dentro das possibilidades e limitações dos conceitos, através da fórmula tat twam asi (isto és tu); (ii) de modo exotérico, aos não iniciados, o povo, esse conhecimento foi traduzido para forma do mito, o que não permite a apreensão direta de tal conhecimento. Schopenhauer, assim, observa que as religiões podem ser entendidas como uma roupagem mítica para exposição do conhecimento que não pode ser apreendido pela tosca inteligência comum. ${ }^{16}$

O mito utilizado para explicar a Justiça Eterna é o mito da transmigração das almas. Esse mito ensina que todos os sofrimentos infligidos em vida pelo homem a outros seres têm de ser expiados em uma vida posterior neste mundo e precisamente pelos mesmos sofrimentos. Em contrapartida, o mito enuncia recompensas pelas boas ações praticadas, como o renascimento em figuras excelentes e mais nobres. ${ }^{17}$ Para Schopenhauer, nunca houve, nem haverá um mito tão intimamente ligado à verdade filosófica. $^{18}$

Contudo, Schopenhauer ainda especula sobre uma possível objeção: "Se em linhas gerais o azar e o erro assenhoram-se sobre a vida humana e sobre o curso do mundo, como pode haver lugar para a justiça?". ${ }^{19}$ A primeira observação a ser feita é a de que não se encontrará a Justiça Eterna na experiência, i.e., no mundo fenomênico. Muito pelo contrário, fenomenicamente os sofrimentos estão repartidos de forma extremamente desigual, assim como os prazeres. ${ }^{20}$ Não existe proporção nem correspondência entre o valor do homem e seu fatídico destino. ${ }^{21}$ A essência da humanidade é a essência do nosso mundo: vontade, i.e., discórdia, contradição, carência, sofrimento.

Por fim, após uma pequena explanação de como Schopenhauer expõe o conceito de Justiça Eterna, pode-se indicar (i) as formas pelas quais ela se revela e é definida, e (ii) o papel sistemático que ela cumpre na filosofia schopenhaueriana.

\footnotetext{
15 "Mal da culpa" e "Mal da pena", respectivamente.

${ }^{16}$ Cf. MVR I, § 63, P. 454, I 420.

${ }^{17}$ Cf. MVR I, § 63, P.454-455, I 420-421.

${ }^{18}$ Cf. MVR I, $\S 63$, P. 455, I 421.

19 MP, Cap.7, P. 119, 302. (Tradução para: „Ueberhaupt beherrschen das Menschenleben und den Weltlauf Zufall und Irrthum: wie sollte da die Gerechtigkeit Raum finden?“)

${ }^{20}$ Cf. MP, Cap. 7, P.119, 302.

${ }^{21}$ Cf. MP, Cap. 7, P.120, 302.
} 
Como exposto, o significado da Justiça Eterna pode ser apreendido ou explicado: do ponto de vista de nossa essência metafísica somos uma mesma Vontade, e, portanto, compartilhamos a mesma essência de sofrimento. Por consequiência, o mundo é um espelho do que somos: somos o que merecemos ser. O sofrimento é a punição pela nossa existência, e a Justiça Eterna é exatamente essa consequiência, essa retaliação / retribuição, ao que somos.

Quanto ao papel sistemático da Justiça Eterna, Schopenhauer aponta duas funções relevantes: (i) a compreensão da relevância ética das ações, e, conseqüentemente, (ii) a compreensão da natureza da virtude e do vício.

A partir do exposto, dar-se-á o objetivo deste pequeno artigo como cumprido se ao leitor ficar claro as linhas gerais da conceituação empreendida pelo filósofo da vontade à Justiça Eterna. Espera-se que os devidos contornos tenham sido dados à exposição ao serem explicitados: (i) o que é e qual o significado da Justiça Eterna, (ii) o ponto de vista que deve ser adotado para o seu correto entendimento, a saber, o ponto de vista transcendental - postura metodológica que evita uma série de equívocos engendrados pela apreciação fenomênica do conceito -, (iii) a apreensão do significado e as duas formas de transmissão da Justiça Eterna, e (iv) a resposta a uma objeção artificial, oriunda da adoção do ponto de vista fenomênico, formulada por Schopenhauer.

Assim, espera-se que tenha ficado claro que a apreensão do significado da Justiça Eterna consiste em perceber que, do ponto de vista transcendental, i.e., do ponto de vista metafísico, somos a mesma essência. E, como consequiência direta da apreensão desse significado, que a Justiça Eterna não é uma equidade ou justiça no sentido de ser um ato retributivo / retaliativo no tempo, espaço e em uma cadeia causal. Ela é retributiva / retaliativa na medida em que é a expressão de uma tautologia e de um paradoxo que enunciam que o mundo só pode ser o que ele não deveria ser; que o mundo só pode ser o que ele tem merecido ser, que o mundo só pode ser o que ele é: Vontade, i.e., contradição, dor, carência, miséria, sofrimento, discórdia, falta. 


\section{Referências bibliográficas}

CARTWRIGHT, D. E. Historical Dictionary of Schopenhauer's Philosophy. In: Historical dictionaries of religions, philosophies, and movements, $\mathrm{n}^{\circ}$. 55; Oxford: Scarecrow Press, 2005.

GODART-VAN DER KROON, A. Schopenhauer's Theory of Justice and its Implication to Natural Law. in: Schopenhauer Jahrbuch, der Schopenhauer-Gesellschaft 2003. Band 84. Frankfurt am Main: Verlag Köningshausen \& Neuman Würzburg, 2003, p. 121-145.

HAMLYM, D.W. Eternal Justice. In: Schopenhauer Jahrbuch, der SchopenhauerGesellschaft 1988. Band 69. Frankfurt am Main: Verlag Waldemar Kramer, 1988, p. 281-288.

PERNIN, M. Schopenhauer - Decifrando o Enigma do Mundo; Trad. de Lucy Magalhães. Rio de Janeiro: Jorge Zahar, 1995.

PHILONENKO, A. Schopenhauer - Una Filosofía de la tragédia. Trad. Gemma Muñoz-Alonso López. Barcelona: Anthropos Editorial Del hombre, 1989.

SCHOPENHAUER, A. Arthur Schopenhauers sämtliche Werke; hrsg. Von Paul Deussen. Munique: R. Piper, 1911-1942.

Arthur Schopenhauers handschriftlicher Nachlaß. Philosophische Vorlesungen - Metaphysik der Sitten. In: SCHOPENHAUER, A. Arthur Schopenhauers sämtliche Werke, vol X; hrsg. Von Paul Deussen. Munique: R. Piper, 1911-1942, p.367584.

Metafísica de las Costumbres; introdução, tradução e notas de

Roberto Rodríguez Aramayo. In: Coleção Clássicos de la Cultura; Madri: Editorial Trotta SA, 2001.

- O Mundo como Vontade e como Representação. Trad. Jair Barboza. São Paulo: EDUSP, 2005.

VECCHIOTTI, I. Schopenhauer. Trad. João Gama. In: Biblioteca Básica de Filosofia. Lisboa: Edições 70, 1990. 